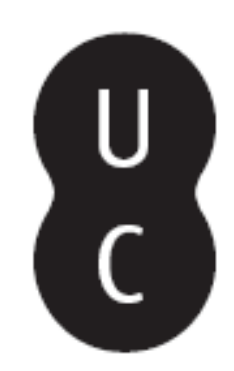

\title{
Pिar TIIIm
}

[Recensão a] Solis, Yves; Savarino, Franco (Coord.) (2011). El anticlericalismo en Europa y América Latina. Una visión transatlântica

Autor(es): $\quad$ Silva, Ivo Pereira da

Publicado por: Imprensa da Universidade de Coimbra

URL persistente:

URI:http://hdl.handle.net/10316.2/38663

DOI:

DOI:http://dx.doi.org/10.14195/1645-2259_15_19

Accessed : $\quad$ 26-Apr-2023 11:35:12

A navegação consulta e descarregamento dos títulos inseridos nas Bibliotecas Digitais UC Digitalis, UC Pombalina e UC Impactum, pressupõem a aceitação plena e sem reservas dos Termos e Condições de Uso destas Bibliotecas Digitais, disponíveis em https://digitalis.uc.pt/pt-pt/termos.

Conforme exposto nos referidos Termos e Condições de Uso, o descarregamento de títulos de acesso restrito requer uma licença válida de autorização devendo o utilizador aceder ao(s) documento(s) a partir de um endereço de IP da instituição detentora da supramencionada licença.

Ao utilizador é apenas permitido o descarregamento para uso pessoal, pelo que o emprego do(s) título(s) descarregado(s) para outro fim, designadamente comercial, carece de autorização do respetivo autor ou editor da obra.

Na medida em que todas as obras da UC Digitalis se encontram protegidas pelo Código do Direito de Autor e Direitos Conexos e demais legislação aplicável, toda a cópia, parcial ou total, deste documento, nos casos em que é legalmente admitida, deverá conter ou fazer-se acompanhar por este aviso.

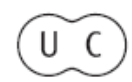




\section{Revista \\ de História \\ da Sociedade \\ e da \\ Cultura}

Século de Ouro

Siglo de Oro 


\section{Solis, Yves; Savarino, Franco (Coord.) (2011). El anticlerica-} lismo en Europa y América Latina. Una visión transatlântica. México: Investigacion/Proa, 395 pp., ISBN: 978-607-484-234-0 (Escuela Nacional de Antropología e Historia), 978-972-836138-9 (CEHR-Universidade Católica Portuguesa)

A obra El anticlericalismo em Europa y América Latina. Una visión transatlântica, organizada por Yves Solis e Franco Savarino é uma produção coletiva que reúne parte das comunicações apresentadas na mesa-redonda cujo tema tratava do Anticlericalismo en America Latina, inserida no XV Congresso Internacional de La Asociación de Historiadores Latinoamericanistas Europeos (AHILA), que ocorreu em Leiden, Paises Baixos, nos dias 26 a 29 de agosto de 2008. A justificativa para a promoção do encontro e a publicação do livro repousa na constatação de que "a pesar de la importancia de este tema, al momento son muy pocas las investigaciones que incluyen uma visión 'global' y comparativa del fenómeno”. Por conseguinte, o argumento/objetivo central da obra é abordar/compreender o anticlericalismo "desde distintos ángulos y diversos lugares” (p. 5). Os coordenadores da obra são especialistas e membros do Seminario Internacional Iglesia, Estado y Sociedad Civil, criado em 2008, na Universidad Iberoamericana Ciudad de México.

O livro está dividido em três partes, distribuídos em onze artigos. $\mathrm{Na}$ primeira parte, denominado de "Asuntos Políticos", são analisados dois casos europeus (Itália e Espanha) e dois latino-americanos (Venezuela e México). O primeiro artigo "Libertad contra Verdad - Tensiones entre liberales y religiosos em la Venezuela del siglo XIX”, escrito pela socióloga Maria Eugenia Talavera, apresenta uma instigante investigação sobre o processo de laicização da nascente república venezuelana. A autora do artigo mostra que, com a independência da Venezuela do jugo da Espanha, os novos dirigentes políticos desejaram extirpar da sociedade a "consciência monárquica, fuertemente atada a la religión católica" (p.16). O auge do processo de laicização do Estado venezuelano ocorreu durante os dezoito anos "de conducción del país del general Antonio Gusmán Blanco", conhecido como o "guzmanato" (18701888). O processo de secularização de Gusmán envolveu a expropriação de bens da Igreja, extinção de conventos masculinos, dissolução das ordens e congregações femininas (1872) e o rompimento com a Santa Sé, assim como a proposta de criação da Igreja nacional Venezuelana. No entanto, o projeto não conseguiu ser completamente implementado, em boa medida em razão da diplomacia do papado e também pela resistência de setores ligados à Igreja 
católica. Com o fim do governo de Gusmán ocorreu uma "viraje em las relaciones entre La Igresia y el Estado” (p.38), onde o coroar dessa nova fase foi a retomada das relações com a Santa Sé e o retorno de diversas ordens religiosas no limiar do século XX.

O segundo artigo, "La "U" o los católicos y las sociedades secretas", assinado por um dos coordenadores da obra Yves Solis, estuda uma organização secreta intitulada de Unión de Católicos Mexicanos, mais conhecida como "U”, fundada em 1915. Analisar as características dessa organização e suas relações com a hierarquia da Igreja, tendo como documento básico as sessioni (atas das reuniões dos prelados solicitadas pelo Papa com a finalidade de resolver conflitos pontuais e urgentes das diferentes nações, documento sob guarda do Arquivo Secreto do Vaticano) é o objetivo central do artigo. A organização da "U" tinha como "missão" fazer uma reação radical ao anticlericalismo do Estado mexicano e implementar uma ordem social cristã. Exigia o segredo absoluto dos membros da organização e disciplina rigorosa. Essa organização procurou atuar em várias frentes: criação de semanários, escolas e, especialmente, na política com o propósito de "cambiar las leys y los gobiernos" (p.54). No entanto, a hierarquia da Igreja em Roma, em especial o delegado apostólico, temia que a organização fosse descoberta e trouxesse consequências para a Igreja e para a nação, além disso, a organização funcionava nos moldes da Maçonaria, o que trazia desconforto para a hierarquia eclesiástica. Aconselhado pela maioria dos cardeais, o papa Pio XI "condenou a associación”, decretando sua extinção (1922).

"Relaciones peligrosas: anticlericalismo, Iglesia y fascismo en Italia" é o título do artigo assinado por Franco Savarino, professor da Escuela Nacional de Antropología e Historia (México), também organizador da obra em análise. Savarino inicia o seu artigo afirmando que um dos assuntos menos conhecidos na história do anticlericalismo moderno foi a postura anticlerical do fascismo italiano nos anos 20 do século XIX. "Em realidad, el fascimo como fenómeno político-cultural de su época - fue para la Iglesia um desafio considerable, por su carácter ideológico laico-pagano y por su gran fuerza de seducción y de arraste entre las masas" (pp. 79-80). Utilizando como aporte teórico as ideias de Emilio Gentile, Savarino afirma que o fascismo foi uma religião política, nesse sentido concorrendo com o catolicismo. É perceptível no fascismo, além do jacobinismo do Risorgimento, características pagãs, sobretudo manifestado no culto ao Estado, prática denunciada pelo Papa Pio XI como uma "statolatría pagana" (p.85). Apesar das características citadas, os dirigentes fascistas aproximaram-se da Igreja Católica, pois percebiam que algumas características do catolicismo - como as noções de hierarquia, 
ordem, submissão, transcendência, assim como a noção de "bien comúm y el de corporación" - eram afinadas com a ideologia fascista. O Estado fascista, reconhecendo as funções civis da religião, incorporará o catolicismo dentro da religião de Estado. "Para ambos, tomar esta senda suponía aceptar unas relaciones peligrosas que podríam afectar el espiritu y el proyecto histórico da la religión política y de la religión tradicional" (p. 94). O autor conclui afirmando que a aproximação do Estado fascista à Igreja Católica era um “matrimonio de interesses", que culminará no Tratado de Latrão (1929) e um sólido apoio católico e eclesiástico ao regime fascista.

O caso do anticlericalismo na Espanha foi o último texto da primeira sessão, assinado por María Pilar Salomón Chéliz, da Universidade de Zaragoza, intitulado "Constuir la identidad nacional desde el anticlericalismo". Chéliz, argumenta que entre os diversos estudos que estabelecem a relação entre religião e nacionalismo, o caso espanhol está ausente. Em face dessa constatação, a autora propõe-se estudar a construção da identidade nacional espanhola a partir do anticlericalismo, em especial o de cariz republicano, que procurou criar a imagem de uma república laica e moderna. A autora reconhece que a obra seminal de René Remond contribuiu para impulsionar "el estudio del anticlericalismo en España sobre nuevas bases" (p.100). Segundo Chéliz, o anticlericalismo chega ao seu apogeu na Espanha no final do século XIX, os republicanos usaram o discurso anticlerical como argumento retórico na sua luta contra a tradição, representada pela monarquia e pelo clericalismo, onde "El anticlericalismo aparecía vinculado en ese discurso a la modernidad y la europeización, dentro de un esquema dualista y maniqueo establecido entre tradición y modernidad: la Iglesia y la monarquía simbolizaban la primera (...); la razón y la ciencia, por el contrario, encarnaban la segunda” (p. 106).

Rita Mendonça Leite no artigo "O anticlericalismo na óptica do protestantismo português" inicia a segunda parte da obra denominada Las cuestiones sociales. Na segunda metade do século XIX, o universo religioso português experimenta uma dinâmica de diferenciação religiosa, com a formação de comunidades cristãs evangélicas, contribuindo para o progressivo e demorado processo de pluralidade religiosa em Portugal. "Essas comunidades participavam então activamente da lenta estruturação do percurso que as conduziria da exclusão até a liberdade de culto" (p.133). Como? Durante o período da Monarquia Constitucional em Portugal o Estado era confessional, amparado por uma população majoritariamente católica, e refletia-se num Parlamento também de maioria católica. $\mathrm{O}$ texto de Mendonça Leite ressalta e analisa a importância qualitativa da minoria quantitativa evangélica. Os protestantes estavam situados num espaço "entre a criminalização, consignada na lei 
constitucional e penal, e a integração progressiva no seio da sociedade portuguesa" (p.117). Como mecanismo de integração, os protestantes desenvolveram espaços de sociabilidade e aproximaram-se metodologicamente dos republicanos. Deste modo, intervieram na sociedade através do ensino, da imprensa, conferências, atividades físicas e através da caridade. $\mathrm{O}$ anticlericalismo protestante estava integrado aos conteúdos teológicos e doutrinários das comunidades evangélicas, era perceptível na sua "construção de uma concepção sócio-cultural antagónica e alternativa ao catolicismo” (p.125). O tradicional antijesuitismo dos anticlericais liberais e republicanos também foi incorporado pelas comunidades protestantes, sobretudo "pelos obstáculos colocados [pelos jesuítas] à pluralidade religiosa e definição da liberdade de cultos" (p.129). Diante do consenso em torno da constatação "que Portugal se encontrava numa situação de crise", os protestantes responsabilizavam os católicos pelo estado do país, apoiaram os republicanos e defenderam a liberdade religiosa e política como caminho para o progresso e superação da crise.

"Entre revolucionarios y católicos: un proyecto de nación, 1913-1917", artigo da historiadora María Gabriela Aguirre Cristiani, analisa-se o anticlericalismo no início da Revolução Mexicana. Em 1911, Francisco Madero lidera um processo revolucionário que colocou termo ao governo ditatorial de Porfírio Diaz. No entanto, dois anos depois, Victoriano Huerta assassinou Madero e assumiu o comando da revolução. Os opositores de Huerta tornaram-se extremamente anticlericais por entenderem que a hierarquia católica apoiara a ação golpista, como consequência "o uso de la violencia fue uma constante" (p.158). No entanto, é importante "matizar que no todos los revolucionarios fueron anticlericales, y los que sí lo fueron lo manifestaron en distintos niveles" (p.159). O clero, nesse contexto, era retratado como "retardatário", "detestable", "un cancer" e deveria ser extirpados da sociedade. Outro aspecto importante no anticlericalismo mexicano estava associado ao fato de que a Igreja colocara em prática as diretrizes da encíclica Rerum Novarum (1892) do Papa Leão XIII, onde a nova doutrina social da Igreja, com sua aproximação às classes trabalhadoras, gerava temor e desconfiança por parte dos revolucionários e "este es probablemente el factor más importante del choque entre Iglesia y Estado em esos años" (p. 161). O programa do catolicismo social colidia com o projeto social revolucionário. A autora conclui afirmando que "el manejo de la 'cuestión social' por parte de la Iglesia influyó significativamente em el proyecto revolucionario, aunque ello significó la radicalización del anticlericalismo" (p. 171).

O cientista político Massino Di Giuseppe aborda o anticlericalismo no período de "institucionalização revolucionária" no México. No artigo "Las 
políticas de 'desfanatización' em el México indígena”, o autor procura traçar a "evolución de las políticas de desfanatización" efetivadas pelo governo federal do México durante o Maximato e a primeira parte da época cardenista (1928-1936). O objetivo central da Desfanatización, segundo Di Giuseppe, era enfraquecer a hierarquia da Igreja Católica e conquistar as mentes e os corações das populações indígenas e rurais, demasiadamente "fanatizadas" pelo clero católico. O presidente Plutarco Elias Calles envidou todos os esforços para secularizar a escola e difundir novos valores associados ao progresso e a modernidade. Na região de Tabasco, o governador Tomás Garrido Canabal, aplicou as ideias de Calles e liderou a mais radical experiência de "desfanatização" dessa época. Diversas medidas anticlericais forma colocadas em prática. No entanto, a resistência da Igreja católica e, principalmente, a oposição das próprias comunidades indígenas foram fundamentais para impedir o avanço desse movimento.

"Anticlericalismo y Cultura" é a terceira parte da obra está composta com quatro artigos. No primeiro texto "Anticlericalismo en el siglo XIX: el periódico El Libre Pensador (1870)”, a historiadora Nora Pérez-Rayón investiga a militância dos livres-pensadores contra o clericalismo na esfera pública mexicana. A autora desenvolve uma reflexão sobre os discursos, projetos e os sonhos de "jóvenes exponentes da la intelectualidad liberal" que "voluntariamente se reuníam a compartir informatión y debatir sobre el presente y el futuro de su país" (p. 10). O artigo é muito interessante por possibilitar comparações dos temas e ideias que circulavam entre os livres-pensadores em diversos países no mesmo período.

A questão dos debates políticos e culturais em Portugal no contexto da decretação da Lei de Separação de 1911 foi o tema do artigo "Para lá do anticlericalismo: a separação das Igrejas do Estado como embate cultural (no contexto da Lei de Separação de 1911)" do teólogo e historiador Sérgio Filipe Ribeiro Pinto. $\mathrm{O}$ autor faz uma excelente síntese da legislação republicana anterior à separação, onde destaca medidas laicizantes em várias áreas como no ensino, registros civis, leis de famílias, etc. A segunda parte do texto é dedicado ao exame pormenorizado da Lei de Separação (1911) que colocou termo a religião de Estado. Para Ribeiro Pinto "o ímpeto laicizador do republicanismo" tinha como propósito "conter a religião dominante, e com ela as demais denominações, para a consecução da revolução cultural (antropológica, política, social) considerada imprescindível para a revitalização de um país decadente" (p. 251). Também evidencia que o conflito entre mundividências antagônicas (republicana e católica) esteve na base e além do anticlericalismo. 
O historiador Tiago Pires Marques em "Religião e anticlericalismo no nascimento da psiquiatria moderna (Portugal e França, c. 1870-c. 1920)”, aborda, de forma inovadora, a temática do anticlericalismo na sua relação com a psicanálise. Nesse artigo analisa-se como muitos psiquiatras, franceses e portugueses, utilizaram a nova ciência da alma com instrumento na luta contra o clericalismo finissecular. "A argumentação 'científica', de cunho psiquiátrico, patologizando certas formas de vida religiosa foi (...) a face mais radical do anticlericalismo em Portugal” (p.297). Os jesuítas foram os alvos principais dos psiquiatras anticlericais, que viam nesse grupo religioso pessoas delirantes, loucas e degeneradas, passíveis de tratamento médico. $\mathrm{O}$ autor conclui que o problema da relação entre loucura e religião nesse contexto "foi um dos vectores de transformação do racionalismo positivista e da formação de uma nova paisagem cultural” (p.318).

$\mathrm{O}$ artigo que encerra a obra é um estudo de caso. O historiador Luciano Ramírez em "Anticlericalismo en uma ciudad conservadora de la província mexicana: 'Aguascalientes en la historia', el polémico mural del Palacio de Gobierno", analisa uma intensa controvérsia envolvendo a hierarquia da Igreja Católica - apoiada por parte de sociedade e da imprensa - e o governo laico de Aguascaliente no México em 1960. O conflito estava ligado à pintura de um mural no Palácio do Governo levado a cabo pelo artista chileno Oswaldo Barra Cunningham, discípulo de Diego Rivera. O mural foi interpretado, por parte de setores ligados a Igreja, como anticlerical. O governo foi acusado, pela imprensa local, de querer fomentar o velho anticlericalismo da década de 1920. A crise termina em 1962, quando um novo governador foi eleito e conseguiu abrandar a polémica, com o passar do tempo "la gente aprendió a valorarlo y respetarlo" (p. 372).

A obra pode ser considerada como uma contribuição significativa, pertinente e necessária para os estudos sobre o anticlericalismo "transatlântico". A qualidade dos artigos é indiscutível. No entanto, percebe-se que a realidade latino-americana poderia ter sido mais bem explorada, inserindo as experiências de outras nações que experimentaram o mesmo fenómeno, como Brasil e Argentina. Outro aspecto que merece consideração é a constatação de que os artigos analisam fundamentalmente o fenómeno do anticlericalismo preso aos limites do Estado nação. As influências europeias e/ou vice-versa são raramente mencionadas.

Ivo Pereira da Silva

Doutorando em História / Capes Universidade de Coimbra / CHSC Universidade Federal do Pará (BR) ivosilva@ufpa.br 